\title{
New criteria for breast symmetry evaluation after breast conserving surgery for cancer
}

\section{Novos critérios para avaliação da simetria da mama após cirurgia conservadora de câncer}

René Aloisio da Costa Vieira ${ }^{1,2,3}$ (D); Gabriele Biller ${ }^{1}$; Fabiola Cristina Brandini da Silva ${ }^{1}$; Jonathas José da Silva ${ }^{1}$; Marco Antônio de Oliveira ${ }^{4}$; ANTÔNIO BAILÃO-JUNIOR ${ }^{5}$.

\section{A B S T R A C T}

\begin{abstract}
Objective: to evaluate symmetry after breast-conserving surgery (BCS) for cancer. Methods: a prospective study of patients undergoing $B C S$. These patients were photographed using the same criteria of evaluation. The references points used were the nipple height difference (NH), the nipple-manubrium distances (NM), nipple-sternum distances (NS) and the angle between the intramammary fold and the nipple (nipple angle; NA). ImageJ software was used. Three breast symmetry models were evaluated: excellent/others (model 1), excellent-good/others (model 2) and others/poor (model 3). The ROC curve was used to select acceptable criteria for the evaluation of symmetry. Decision tree model analysis was performed. Results: a total of 274 women were evaluated. The BCCT.core result was excellent in $5.8 \%$ (16), good in $24.1 \%$ (66), fair in 46.4\% (127) and poor in 23.7\% (65). The difference in NH was associated with good breast area (0.837-0.846); acceptable differences were below $3.1 \mathrm{~cm}$, while unacceptable values were greater than $6.4 \mathrm{~cm}$. Differences in the NM were associated with average breast area (0.709-0.789); a difference in value of less than $4.5 \mathrm{~cm}$ was acceptable, while values greater than $6.3 \mathrm{~cm}$ were unacceptable. In the decision tree combined model, a good-excellent outcome for patients with differential (d) $\mathrm{dNH}=1(0$ to $5.30 \mathrm{~cm})$ and $\mathrm{dNM} \neq 3(<6.28 \mathrm{~cm})$; and for a poor/poor result, values $\mathrm{dNM}=3(>6.35)$. Conclusions: the results presented here are simple tools that can assist the surgeon for breast symmetry evaluation.
\end{abstract}

Keywords: Breast Neoplasms. Conservative Treatment. Mastectomy, Segmental. Body Image. ROC Analysis.

\section{INTRODUCTION}

$\mathrm{B}$ reast cancer is associated with half of all cancer cases and $38 \%$ of cancer-related deaths in developed countries $^{1}$. It is estimated that over 1.7 million new breast cancer cases are diagnosed annually worldwide. Breast-conserving surgery $(B C S)^{2,3}$ combined with radiotherapy ${ }^{2-4}$ is considered safe. Overall, $57 \%$ of women diagnosed in the early stages and $13 \%$ of those diagnosed in the late stages of the disease undergo breast-conserving treatment, and most undergo radiotherapy ${ }^{5}$.

For patients who undergo BCS, cosmesis is considered excellent or good in $76.3 \%$ and $47 \%$ of cases, respectively ${ }^{6}$. The main factors associated with asymmetry are age, higher body mass index and large tumour size`. Many patients undergo further breast surgery due to asymmetry, and after the second procedure, $94.5 \%$ and $88.8 \%$ of patients are satisfied after 1 and 5 years, respectively. However, a second and a third operation are required in $19.1 \%$ and $6.4 \%$ of cases, respectively ${ }^{8}$.

Women are generally dissatisfied with their breasts, with $42.7 \%$ reporting being displeased ${ }^{9}$, and $30 \%$ of women who undergo BCS are not satisfied with the aesthetic results ${ }^{10}$. Although there are some parameters for healthy breasts ${ }^{9}$, in cosmetic surgical skin marking, other particular reference points and distances are considered appropriate ${ }^{11}$.

Cosmetic evaluation is very subjective, and inter-examiner correlation is poor. Inter-examiner variation can be minimized after a consensus is reached

1 - Hospital de Câncer de Barretos, Programa de Pós-graduação em Oncologia - Barretos - SP - Brasil 2 - Universidade Estadual Paulista (UNESP), Faculdade de Medicina de Botucatu, Programa de Pós-graduação em Tocoginecologia - Botucatu - SP - Brasil 3 - Hospital de Câncer de Muriaé, Departamento de Cirurgia. Divisão de Mastologia - Muriaé - MG - Brasil 4 - Hospital de Câncer de Barretos, Núcleo de Apoio ao Pesquisador - Barretos - SP - Brasil 5 - Hospital de Câncer de Barretos, Departamento de Mastologia e Reconstrução Mamária - Barretos - SP - Brasil 
among examiners, but this is difficult to achieve in clinical practice ${ }^{12}$. Breast Cancer Conservative Treatment Cosmetic Results (BCCT.core) was created to evaluate BCS results ${ }^{13,14}$. This software has led to a $70 \%$ correlation between examiners ${ }^{15}$. Although BCCT.core is extremely useful and reproducible, this tool is used only in research, which suggests that simpler and more objective breast symmetry evaluation criteria are needed. Health professionals and patients do not always consider the same results to be satisfactory ${ }^{16}$, which indicates that more studies are needed in this area.

\section{MATERIALS AND METHODS}

This was a prospective study that was approved by the Barretos Cancer Hospital Research Ethics Committee (No. 782/2014). A total of 300 patients with breast cancer were randomly and systematically selected at the Mastology and Breast Reconstruction Department - Barretos Cancer Hospital between 05/2015 and $06 / 2016$. Patients were selected based on inclusion criteria, and they agreed to participate in all the study phases that evaluated quality of life and sequelae related to cancer treatment (breast cosmesis, lymphedema, and shoulder mobility) and were interviewed and underwent a rigorous clinical evaluation ${ }^{17}$. This study was supported by "Fundação de Amparo a Pesquisa do Estado de São Paulo (FAPESP; No. 08197-0-0/2014)", and multiple evaluations were performed. Part of this study (evaluating quality of life ${ }^{17}$ and breast cosmesis $^{18}$ ) was previously published.

The following patients were considered for inclusion: patients who received treatment exclusively at $\mathrm{HCB}$, those who underwent BCS and radiotherapy for a period exceeding 1 year and patients who provided the written informed consent. Patients with metastatic disease, with recurrence, receiving chemotherapy, with bilateral breast cancer, who were male and with a high number of comorbidities were excluded.

After providing informed consent, the selected patients were taken to a special room containing a background symmetrograph, where points were marked on the sternal manubrium and $20 \mathrm{~cm}$ inferiorly. The women were photographed from a distance of 1 metre using a Cyber-Shot DSC-H300 camera with an 8-megapixel resolution. Photographs were obtained bilaterally in an anteroposterior, lateral direction, until the mid-axillary line could be seen, as this is associated with the evaluation of the areolar angle and the pencil drop angle (PDA) ${ }^{9}$. While analysing the photographs, patients whose images were not suitable for evaluation using BCCT.core were excluded, along with patients who underwent central BCS without areolar reconstruction.

BCCT.core was used for the cosmetic evaluation ${ }^{14,19}$. The BCCT.core program performs automatic calculations of different ratios/asymmetries, including the breast volume, skin colour and scarring. The results are given with a 4-point scale (1-excellent, 2-good, 3-fair, and 4-poor) ${ }^{15,19}$. These parameters were used as the standard (Figure 1).

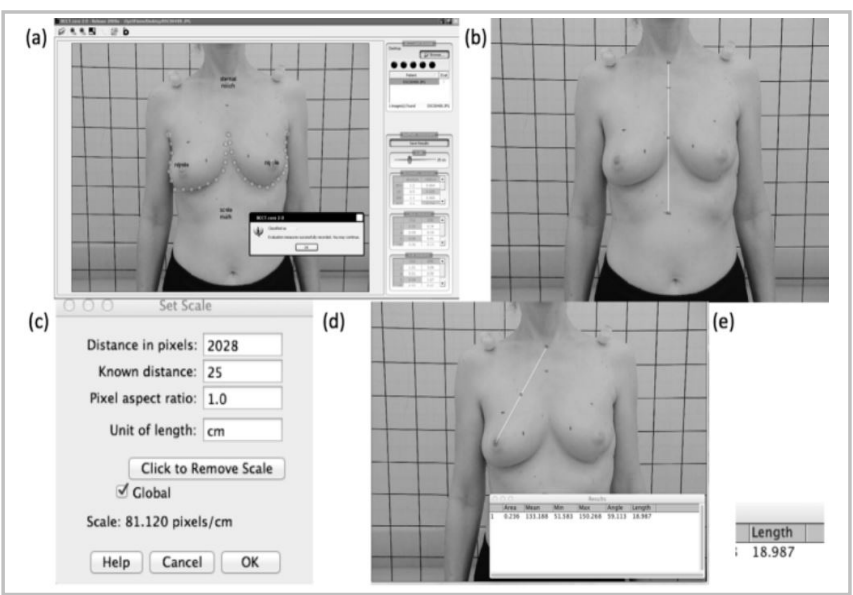

Figure 1. Image parameters. (a) BCCT.core; (b and c) ImageJ calibration; $(d, e)$ analysis and results in $\mathrm{cm}$.

The same images were also evaluated with ImageJ software, which was used to evaluate the following distances after calibrating the equipment with known distances: the nipple-manubrium (NM) distance, the nipple angle (NA), the nipple-sternum (NS) distance and the angle of the abducting arm associated with the pencil test (PDA). These measurements were based on a previous study ${ }^{9}$, and for this, the differences of the distances between the nipple-manubrium (NM), the nipple-sternum (NS), the angles between nipples (NA) and the nipple height (NH) were considered. To evaluate the primary breast shape, the contralateral breast (healthy) was evaluated, and ptosis was evaluated with the pencil test (the angle at which a pencil placed 
under the breast falls with upper limb abduction), the contralateral NM (CNM) and the contralateral NA (CNA). The measurements are shown in figure 2 . As there are no criteria in the literature regarding this evaluation, this was considered a pilot study, and we did not perform sample size calculations.

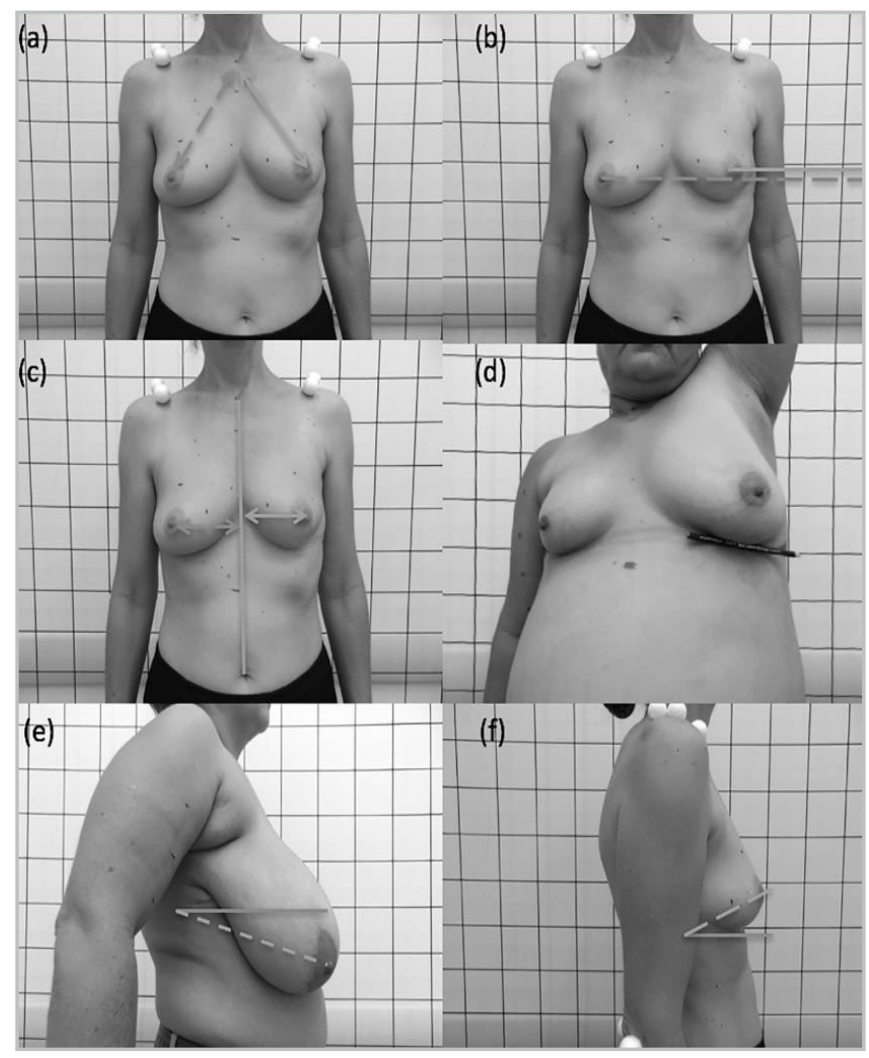

Figure 2. Breast measurement parameters. (a) NM; (b) difference in the $\mathrm{NH}$; (c) NS difference; (d) PDA with arm abduction; (e) negative NA; and (f) positive NA.

BCCT.core output and ImageJ calculations were first transferred to the IBM SPSS for Mac $®$ program, which was used to perform differential calculations. Subsequently, these data were exported to the MedCalc ${ }^{\circledR}$ program, where the findings related to breast symmetry were dichotomized into excellent/others (model 1), excellent-good/others (model 2) or excellent-good-fair/ poor (model 3). The receiver operating characteristic (ROC) curve was used to evaluate the sensitivity, specificity, area and difference in the cut-off point between acceptable and non-acceptable symmetry to identify simple criteria related to good breast symmetry.

From the identified criteria, we opted to analyse those that presented better results for all cut-off points and presented an increasing linearity in relation to the results in the ROC curve. Accordingly, only the difference between the $\mathrm{NH}$ and the difference in the NM distance were selected for the construction of a mathematical model. In the IBM SPPS program, a decision tree was used (decision trees; machine learning). The results of BCCT. core were selected and compared with the differences presented above. The $\mathrm{CHi}$-squared Automatic Interaction Detection (CHAID) method was used in two situations: automatic and forcing the inclusion of the two variables in the model. Due to the limited number of patients with excellent criteria, we chose to group the BCCT. core results into excellent-good. In the tree model, the orientation was descending, presenting the classification results according to the association or lack of association of the values.

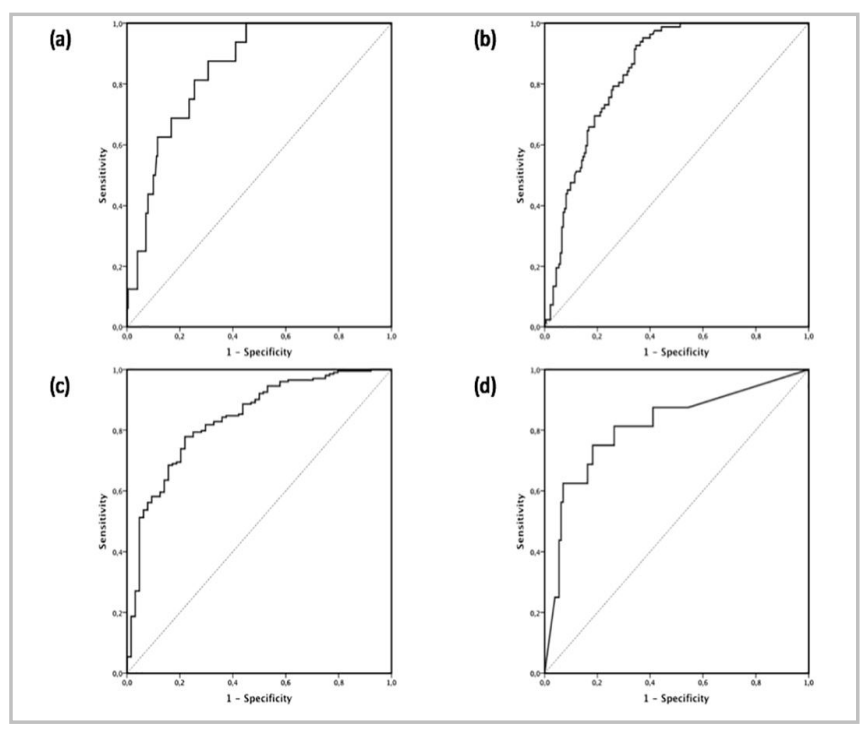

Figure 3. ROC curve for the results: (a) $d N M$ in model 1; (b) $d N M$ in model 2; (c) dNM in model 3; (d) breast shape according to the PDA evaluation with excellent results.

\section{RESULTS}

Of the 300 patients selected for the study, 3 (1\%) patient photographs had inadequate resolution, and $23(7.7 \%)$ underwent central BCS without areolar reconstruction, which resulted in 274 patients who were eligible for inclusion in the study.

The age of the patients ranged from 25.8 to 87.5 years (mean 58.4, standard deviation (SD) 9.8), and patients had undergone breast surgery 1 to 20.2 years prior to the study (mean 6.9; SD 4.1). Overall, 50.4\% of tumours were located in the right breast. Tumour 
sizes ranged from 0.3 to $11 \mathrm{~cm}$ (mean 2.4, SD 1.5). Approximately $33.2 \%$ of tumours occupied 2 quadrants. The tumours were determined to have the following T-TNM stages: $4.0 \%$ Tis, $42.3 \% \mathrm{~T} 1,43.1 \% \mathrm{~T} 2,7.7 \% \mathrm{~T} 3$ and $2.9 \% \mathrm{~T} 4$. In terms of histology, $87.6 \%$ of women had invasive ductal carcinoma, $4.7 \%$ had invasive lobular carcinoma, $4.0 \%$ had ductal carcinoma in situ, and $3.6 \%$ had other breast cancer histologies. All patients underwent $\mathrm{BCS}$ and subsequent chest wall radiotherapy. A total of $14.6 \%$ (40) of patients underwent procedures with different oncoplastic surgical techniques, and $12 \%$ underwent symmetrisation surgeries, of which $9.1 \% 25$ were concomitant and $2.9 \%{ }^{8}$ were performed at a later date.

When the differential values were compared between the sides (Table 1), the sternal-manubrium difference ranged from 0 to $18.8 \mathrm{~cm}$ (mean 4.50, SD 3.32), the $\mathrm{NH}$ difference ranged from 0 to $21.7 \mathrm{~cm}$ (mean 5.40, SD 3.70), the NA difference ranged from 0 to $55.2^{\circ}$ (mean $17.1^{\circ} ;$ SD $12.4^{\circ}$ ), and the difference between the sternum and nipple ranged from 0 to 10.8 $\mathrm{cm}$ (median 2.70, SD 2.10). When the conformational aspects of the contralateral breast were evaluated, it was observed that the PDA ranged from 0 to $180^{\circ}$ (mean $142^{\circ}, \mathrm{SD} 47.7^{\circ}$ ), that the NM distance ranged from 19.2 to $60.0 \mathrm{~cm}$ (mean 31.1, SD 6.39) and that the nipple angle ranged from $-23.0^{\circ}$ to $34.3^{\circ}$ (mean 8.22, SD $\left.10.7^{\circ}\right)$. For these parameters, there were data missing for 0 to 11 (4\%) patients, with a median of 4 (1.4\%) patients.

Table 1. Acceptable criteria for the evaluation of breast symmetry after breast-conserving treatment.

\begin{tabular}{|c|c|c|c|c|c|c|c|}
\hline & Model & Sensitivity & Specificity & Cut-off & $\begin{array}{l}\text { Area under } \\
\text { the ROC } \\
\text { curve }\end{array}$ & $\mathrm{Cl}$ & $p$ \\
\hline \multicolumn{8}{|l|}{ Difference } \\
\hline & 1 & 87.5 & 69.3 & $\leq 3.1 \mathrm{~cm}$ & 0.846 & $0.774-0.919$ & $<0.0001$ \\
\hline \multirow[t]{3}{*}{ Nipple height (NH) } & 2 & 92.7 & 65.4 & $\leq 5.3 \mathrm{~cm}$ & 0.844 & $0.798-0.889$ & $<0.0001$ \\
\hline & 3 & 77.8 & 78.1 & $\leq 6.4 \mathrm{~cm}$ & 0.837 & $0.781-0.894$ & $<0.0001$ \\
\hline & 1 & 93.7 & 42.5 & $\leq 4.7 \mathrm{~cm}$ & 0.682 & $0.580-0.784$ & 0.014 \\
\hline \multirow[t]{3}{*}{ Nipple-manubrium (NM) } & 2 & 89.0 & 47.9 & $\leq 5.0 \mathrm{~cm}$ & 0.709 & $0.648-0.771$ & $<0.0001$ \\
\hline & 3 & 83.9 & 64.6 & $\leq 6.3 \mathrm{~cm}$ & 0.789 & $0.720-0.857$ & $<0.0001$ \\
\hline & 1 & 93.7 & 40.9 & $\leq 20.2 \mathrm{~cm}$ & 0.625 & $0.525-0.724$ & 0.016 \\
\hline \multirow[t]{3}{*}{ Nipple angle (NA) } & 2 & 77.8 & 46.2 & $\leq 20.2 \mathrm{~cm}$ & 0.595 & $0.524-0.666$ & 0.009 \\
\hline & 3 & 66.8 & 51.6 & $\leq 20.6 \mathrm{~cm}$ & 0.583 & $0.500-0.666$ & 0.050 \\
\hline & 1 & - & - & - & 0.565 & $0.414-0.716$ & 0.41 \\
\hline \multirow[t]{2}{*}{ Nipple-sternum (NS) } & 2 & - & - & - & 0.562 & $0.486-0.639$ & 0.110 \\
\hline & 3 & 60.1 & 68.7 & $\leq 2.2 \mathrm{~cm}$ & 0.673 & $0.600-0.746$ & $<0.0001$ \\
\hline \multicolumn{8}{|l|}{ Contralateral breast shape } \\
\hline & 1 & 75.0 & 81.6 & $\leq 112^{\circ}$ & 0.813 & $0.689-0.937$ & $<0.0001$ \\
\hline \multirow[t]{3}{*}{ Pencil drop angle } & 2 & 72.0 & 50.7 & $\leq 158^{\circ}$ & 0.654 & $0.582-0.726$ & $<0.0001$ \\
\hline & 3 & 53.6 & 75.4 & $\leq 144^{\circ}$ & 0.634 & $0.562-0.706$ & 0.001 \\
\hline & 1 & 100.0 & 48.4 & $>6.9^{\circ}$ & 0.736 & $0.649-0.824$ & 0.002 \\
\hline \multirow[t]{3}{*}{ Nipple angle* } & 2 & 72.0 & 57.4 & $>8.1^{\circ}$ & 0.676 & $0.607-0745$ & $<0.0001$ \\
\hline & 3 & 51.9 & 70.3 & $>9.1^{\circ}$ & 0.615 & $0.539-0.692$ & 0.005 \\
\hline & 1 & 75.0 & 69.4 & $\leq 27.8 \mathrm{~cm}$ & 0.733 & $0.622-0.845$ & 0.002 \\
\hline \multirow[t]{2}{*}{ Nipple-manubrium } & 2 & 82.9 & 44.4 & $\leq 32.7 \mathrm{~cm}$ & 0.652 & $0.582-0.721$ & $<0.0001$ \\
\hline & 3 & 68.9 & 61.5 & $\leq 32.1 \mathrm{~cm}$ & 0.684 & $0.613-0.756$ & $<0.0001$ \\
\hline
\end{tabular}

Model 1 - excellent $x$ others; Model 2 - excellent/good x others; Model 3 - excellent/good/fair x poor; Cl - confidence interval.

*A higher result indicates a more positive value for each test. 
According to BCCT.core, the result was excellent in $5.8 \%{ }^{16}$, good in $24.1 \%{ }^{66}$, fair in $46.4 \%$ (127) and poor in $23.7 \%$ (65) of patients.

When the criteria related to differences between measurements were evaluated, 2 analyses attracted our attention: the difference in the NM distance and the difference in the $\mathrm{NH}$ distance. According to the $\mathrm{NH}$ difference criterion, the results were good regardless of the model used. Measurements below 3.1 $\mathrm{cm}$ were considered optimal, and results worsened as the distance increased; the worst results were observed when the difference in this distance was greater than $6.4 \mathrm{~cm}$. In terms of the difference in the NM distance, the results were average, in relation to models 2 and 3 , and better results were observed when the difference in this distance was less than $5.0 \mathrm{~cm}$. Worse results were also associated with an increase in this distance, and poorer results were observed with a differential distance greater than $6.3 \mathrm{~cm}$ (Table 1).
When the conformational breast data were evaluated and when the contralateral breast served as a reference, a good parameter in relation to the PDA and CNA was observed only in model 1 (excellent $x$ others), while an average relationship was observed with respect to the CNM distance and CNA (Table 1).

In the combined decision tree model (Tables 2 and 3), the estimated decision rule suggested that a good-excellent outcome for patients with differential (d) $\mathrm{dNH}=1(0$ to $5.30 \mathrm{~cm})$ and $\mathrm{dNM} \neq 3(<6.28 \mathrm{~cm})$ with a $56.1 \%$ probability. For a reasonable result, it suggested that $\mathrm{dNH}=2$ or $3(>5.36 \mathrm{~cm})$ and $\mathrm{dNM} \neq 3(<6.28 \mathrm{~cm})$, with a probability of $68.0 \%$. For a poor/poor result, dNM $=3$ (> 6.35), with a $56.0 \%$ probability. In the simple model, the dNM variable was excluded from the model. Patients with $\mathrm{dNH}=1(<5.30 \mathrm{~cm})$ presented a $51.6 \%$ probability for an excellent/good result, and patients with $\mathrm{dNH}=2$ or $3(>5.36 \mathrm{~cm})$ presented a probability of a poor/poor outcome of $46 \%$.

Table 2. Reference values for $d N H$ and $d N M$.

\begin{tabular}{lcccc}
\hline Model & Points & & dNH & dNM \\
\hline 4 points & 1 & Excellent & 3.1 to 0 & 4.68 to 0 \\
& 2 & Good & 5.30 to 3.32 & 4.99 to 4.71 \\
3 points & 3 & Fair & 6.40 to 5.36 & 6.28 to 5.02 \\
& 4 & Poor & 21.66 to 6.46 & 18.79 to 6.35 \\
& 1 & Excellent/Good & 5.30 to 0 & 4.99 to 0 \\
& 2 & Fair & 6.40 to 5.36 & 6.28 to 5.02 \\
& 3 & Poor & 21.66 to 6.46 & 18.79 to 6.35 \\
\hline
\end{tabular}

d-differential; $N H$ - nipple height; $N M$ - nipple-manubrium.

Table 3. Results of the decision tree based on the probability of different combinations.

\begin{tabular}{lccccc}
\hline Model & & \multicolumn{4}{c}{ Prediction } \\
\cline { 3 - 5 } Simple & Observed & Excellent/good & Fair & Poor & $\%$ correct \\
& Excellent/good & 81 & 0 & 1 & $98.8 \%$ \\
& Fair & 78 & 0 & 45 & 0 \\
Forced & Poor & 16 & 0 & 49 & $75.4 \%$ \\
& \% General & $64.8 \%$ & $0 \%$ & $35.2 \%$ & $48.1 \%$ \\
& Excellent/good & 73 & 4 & 5 & $89.0 \%$ \\
& Fair & 51 & 44 & 28 & $35.8 \%$ \\
& Poor & 6 & 17 & 42 & $64.6 \%$ \\
& $\%$ General & $48.1 \%$ & $24.1 \%$ & $27.8 \%$ & $58.9 \%$ \\
\hline
\end{tabular}




\section{DISCUSSION}

Currently, no universal criteria for breast symmetry have been established. The evaluation of the literature related to plastic and reconstructive surgery has revealed some parameters that may be considered appropriate. The reference points are the midclavicularareola line $(20$ to $21 \mathrm{~cm})$, the sternal notch-areola line (19 to $24 \mathrm{~cm}$ ), the areola-sulcus line $(4$ to $6 \mathrm{~cm}$ ) and the areola-sternum line $(8 \text { to } 12 \mathrm{~cm})^{11}$. When normal breasts are evaluated, one should consider patient preferences with respect to their desire for symmetry, and the healthy breast should be evaluated only after the diseased breast has received treatment in an attempt to perform similar procedures.

BCS has acceptable recurrence rates when combined with radiotherapy ${ }^{2,3}$ but can be associated with local changes and sequelae ${ }^{20}$. Asymmetry can occur due to the simple absence of symmetrisation at the time of primary surgery and/or as a result of local changes, and the results deteriorate over time ${ }^{21}$.

Oncoplastic surgery for BCS may be used to treat large tumours and can result in wide margins without concomitant increases in complication rates $22-24$. It is notable that in this study, oncoplasty was performed in only $14.6 \%$ of patients, while symmetrisation was performed in only $12 \%$. This finding suggests that the need for contralateral breast treatment to obtain symmetry should be considered. Of the 23 patients with central tumours, 16 (70\%) underwent oncoplastic surgery with a plug-flap, and in the absence of the areola, the BCCT.core calculation may have been impaired, which would have resulted in a reduced incidence of oncoplasty in this study.

A second detail to consider is the long period between the initial surgical procedure and evaluation, which was 6.9 years on average. The breast shape changes over time, and weight increases accentuate differences, especially in the treated breast, because the volume increase in an irradiated breast is smaller than that in an untreated breast due to tissue fibrosis after radiotherapy.

When factors related to breast asymmetry in patients undergoing BCS are evaluated, younger age, bulky tumours 7,25, menopausal status, tumour size, percentage of skin resected, scar orientation ${ }^{25}$, maximum dose of breast radiotherapy ${ }^{26}$, body mass and tumours located in the superomedial and inferolateral quadrant were all associated with greater asymmetry ${ }^{7}$. Patients with marked asymmetry are more likely to want to undergo a breast symmetrisation procedure ${ }^{7}$.

Patient self-evaluations tend to be better than objective findings from a cosmetic point of view ${ }^{27}$. When patient evaluations were compared with objective metric measurements and evaluations by a panel of observers, the key findings were discordant ${ }^{28}$. Current methodologies have attempted to evaluate breast symmetry using three-dimensional calculations ${ }^{29,30}$. Soror et al. sought to present a methodology based on the creation of triangles and comparative data between breasts ${ }^{31}$. Studies based on magnetic resonance imaging $(\mathrm{MRI})^{32}$ and threedimensional technology evaluations ${ }^{30,33,34}$ are difficult to incorporate in clinical practice. The Breast Analysing Tool $(B A T)^{21}$ software and BCCT.core ${ }^{35}$ were created. Although $B C C T$.core use has progressively increased ${ }^{36}$, universal criteria for the evaluation of symmetry are lacking. We described simple parameters that can be used. A ROC curve evaluation demonstrated that the results were acceptable when the area was greater than 0.7; these results may be excellent (area $\geq 0.9$ ), good (09>area $\geq 0.8$ ) or average $(0.8>$ area $\geq 0.7)$. In terms of the differential values between sides, the NM and $\mathrm{NH}$ differences should be mentioned. In addition, an increase in distance was associated with poorer results, and both good and average area values were observed. Differential values of $3.1 \mathrm{~cm}$ in the $\mathrm{NH}$ and $4.7 \mathrm{~cm}$ in the $\mathrm{NM}$ were associated with excellent results, and these are parameters are easy to use in clinical practice. The remaining methodological differences were not satisfactory.

Regarding the breast shape, PDA values higher than $112^{\circ}$, an NM distance greater than $27.8 \mathrm{~cm}$ and an NA of less than $6.9^{\circ}$ were associated with more ptosis of the breast, which is associated with worse outcomes. Matthes et al. ${ }^{9}$ sought to establish simple and easy evaluation parameters that were considered acceptable in normal women. They noted that an NM distance of less than $25 \mathrm{~cm}$, a positive nipple to intramammary fold distance and a PDA less than or equal to $90^{\circ}$ were associated with $93 \%$ patient satisfaction.

The limitations of this study include the lack of 
patient evaluation before treatment, the long monitoring period, the limited number of patients undergoing symmetrisation and the lack of validation calculations in another patient sample. As this was a pilot study, sample size calculations were not performed, but a convenience sample was used in an effort to identify differential values in a larger sample of patients. Additionally, potential differential values in breast asymmetry were evaluated as opposed to factors related to symmetry. In this regard, patients with excellent results tended to be younger (51.4 years of age, SD 8.5), and the results worsened with increasing age (60.5 years of age, SD 8.8 years with poor outcomes). Furthermore, a proportionately greater number of patients in this group underwent breast symmetrisation $(18.8 \%, p=0.08)$.
We presented a simple method based on patient photography, which may be used to evaluate $\mathrm{BCS}$ results. This method is based on a combination of differences related to the $\mathrm{NH}$ and $\mathrm{NM}$ distances. Although more studies using the same methodology are necessary, we hope that this simple method will help surgeons in clinical practice.

\section{CONCLUSION}

Using simple points, it was possible to identify parameters that are related to acceptable and unsatisfactory results, which can facilitate the identification and selection of patients for secondary breast correction and symmetrisation surgery.

\title{
R E S U M O
}

\begin{abstract}
Objetivo: avaliar simetria após a cirurgia conservadora da mama (CCM) para câncer. Métodos: estudo prospectivo de pacientes submetidos à CCM, as quais foram fotografadas segundo os mesmos critérios de avaliação. Os pontos de referência utilizados foram a diferença de altura do mamilo ( $A M)$, a distância mamilo-manúbrio (MM), a distância mamilo-esterno (ME) e o ângulo entre o sulco intramamário e o mamilo (ângulo mamilo; AnM). Foi usado o programa ImageJ. Avaliamos três modelos de simetria mamária: excelente/outros (modelo 1), excelente-bom/outros (modelo 2) e outros/ruim (modelo 3). Aplicamos a curva ROC para selecionar os critérios aceitáveis para a avaliação da simetria. Realizamos análise com o modelo de árvore de decisão. Resultados: foram avaliadas 274 mulheres. Os resultados do BCCT.core foram excelentes em 5,8\% (16), bons em 24,1\% (66), regulares em 46,4\% (127) e ruins em 23,7\% (65). A diferença de AM (dAM) foi associada a boa área mamária (0,837-0,846); diferenças aceitáveis foram inferiores a $3,1 \mathrm{~cm}$, enquanto os valores inaceitáveis foram superiores a 6,4 cm. As diferenças $M M(d M M)$ foram associadas à área regular das mamas (0,709-0,789); diferença de valor inferior a 4,5 cm foi aceitável, enquanto valores superiores a $6,3 \mathrm{~cm}$ foram inaceitáveis. 0 modelo combinado de árvore de decisão demonstrou resultado bom-excelente para pacientes com diferencial (d) dAM = 1 ( 0 a 5,30 $\mathrm{cm})$ e $d M M \neq 3(<6,28 \mathrm{~cm})$, e resultado ruim/ruim com $d M M=3(>6,35 \mathrm{~cm})$. Conclusões: os resultados aqui apresentados são ferramentas simples que podem auxiliar o cirurgião na avaliação da simetria mamária.
\end{abstract}

Palavras chave: Neoplasia da Mama. Tratamento Conservador. Mastectomia Segmentar. Imagem Corporal. Análise ROC.

\section{REFERENCES}

1. Torre LA, Bray F, Siegel RL, Ferlay J, Lortet-Tieulent J, Jemal A. Global cancer statistics, 2012. CA Cancer J Clin. 2015;65(2):87-108.

2. Fisher $B$, Anderson $S$, Bryant J, Margolese RG, Deutsch $M$, Fisher ER, et al. Twenty-year follow-up of a randomized trial comparing total mastectomy, lumpectomy, and lumpectomy plus irradiation for the treatment of invasive breast cancer. N Engl J Med. 2002;347(16):1233-41.

3. Veronesi $U$, Cascinelli $N$, Mariani L, Greco $M$, Saccozzi R, Luini A, et al. Twenty-year follow-up of a randomized study comparing breast-conserving surgery with radical mastectomy for early breast cancer. N Engl J Med. 2002;347(16):1227-32.

4. Veronesi $U$, Luini $A$, Del Vecchio $M$, Greco $M$, Galimberti V, Merson $M$, et al. Radiotherapy after breast-preserving surgery in women with localized cancer of the breast. N Engl J Med. 1993;328(22):1587-91.

5. Siegel R, DeSantis C, Virgo K, Stein K, Mariotto A, Smith $T$, et al. Cancer treatment and survivorship statistics, 2012. CA Cancer J Clin. 2012;62(4):22041.

6. Kelemen G, Varga Z, Lazar G, Thurzo L, Kahan Z. Cosmetic outcome 1-5 years after breast conservative surgery, irradiation and systemic therapy. Pathol Oncol Res. 2012; 18(2):421-7.

7. Waljee JF, Hu ES, Newman LA, Alderman AK. 
Predictors of breast asymmetry after breastconserving operation for breast cancer. J Am Coll Surg. 2008;206(2):274-80.

8. Fitoussi $A D$, Berry MG, Couturaud B, Falcou MC, Salmon RJ. Management of the post-breastconserving therapy defect: extended follow-up and reclassification. Plast Reconstr. 2010;125(3):78391.

9. Matthes Ado C, Sgrignoli RB. Definition of mammary eutrophy for women in the menacme. Rev Lat Am Enfermagem. 2009;17(1):108-12.

10. Urban C, Lima R, Schunemann E, Spautz C, Rabinovich I, Anselmi K. Oncoplastic principles in breast conserving surgery. Breast. 2011; 20 Suppl 3:S92-5.

11. Shestak KC. Breast Aesthetics in the nonperated and reoperative breast. In: Shestak KC, ed. Reoperative Plastic Surgery of the Breast, Vol. 1. Philadelphia: Lippincott Williams \& Wilkins; 2006. pp. 17-63.

12. Cardoso MJ, Cardoso J, Santos AC, Barros H, Cardoso de Oliveira M. Interobserver agreement and consensus over the esthetic evaluation of conservative treatment for breast cancer. Breast. 2006;15(1):52-7.

13. Cardoso MJ, Cardoso JS, Wild T, Krois W, Fitzal F. Comparing two objective methods for the aesthetic evaluation of breast cancer conservative treatment. Breast Cancer Res Treat. 2009; 116(1):149-52.

14. Cardoso MJ, Magalhaes A, Almeida T, Costa S, Vrieling C, Christie D, et al. Is face-only photographic view enough for the aesthetic evaluation of breast cancer conservative treatment? Breast Cancer Res Treat. 2008; 112(3):565-8.

15. Cardoso MJ, Cardoso J, Amaral N, Azevedo I, Barreau L, Bernardo $M$, et al. Turning subjective into objective: the BCCT.core software for evaluation of cosmetic results in breast cancer conservative treatment. Breast. 2007; 16(5):456-61.

16. Zucca-Matthes G, Vieira RAC. The value of patient's expectation for oncoplastic breast surgery. The Breast J. 2014; 20(6):676-678.

17. Brandini da Silva FC, Jose da Silva J, Sarri AJ, Paiva CE, Aloisio da Costa Vieira R. Comprehensive Validation Study of Quality-of-Life Questionnaire Using Objective Clinical Measures: Breast Cancer
Treatment Outcome Scale (BCTOS), Brazilian Portuguese Version. Clin Breast Cancer. 2019; 19(1):e85-e100.

18. Olivieira-Junior I, Silva IA, Silva $F C B$, Silva JJ, Sarri AJ, Paiva CE, et al. Oncoplastic surgery in breast-conserving treatment: patient profile and impact in quality of life. Breast Care. 2020. doi: 10.1159/000507240.

19. Heil J, Carolus A, Dahlkamp J, Golatta M, Domschke $C$, Schuetz F, et al. Objective assessment of aesthetic outcome after breast conserving therapy: subjective third party panel rating and objective BCCT.core software evaluation. Breast. 2012;21(1):61-5.

20. Vieira RAC, Silva FCB, Biller G, J.S. S, Paiva CE, Sarri AJ. Instruments of quantitative and qualitative evaluation of breast cancer treatment sequels. Rev Bras Mastol. 2016; 26(3):126-32.

21. Reilley AF. Breast asymmetry: classification and management. Aesthet Surg J 2006; 26(5):596-600.

22. Down SK, Jha PK, Burger A, Hussien MI. Oncological advantages of oncoplastic breast-conserving surgery in treatment of early breast cancer. Breast J. 2013;19(1):56-63.

23. Franceschini G, Terribile D, Magno S, Fabbri C, Accetta C, Di Leone A, et al. Update on oncoplastic breast surgery. Eur Rev Med Pharmacol Sci. 2012;16(11):1530-40.

24. Chang MM, Huston T, Ascherman J, Rohde C. Oncoplastic breast reduction: maximizing aesthetics and surgical margins. Int J Surg Oncol. 2012;2012:907576.

25. Taylor ME, Perez CA, Halverson KJ, Kuske RR, Philpott GW, Garcia DM, et al. Factors influencing cosmetic results after conservation therapy for breast cancer. Int J Radiat Oncol Biol Phys. 1995;31(4):753-64.

26. Yu T, Eom KY, Jang NY, Kim KS, Koo TR, Kwon J, et al. Objective Measurement of Cosmetic Outcomes of Breast Conserving Therapy Using BCCT.core. Cancer Res Treat. 2016;48(2):491-8.

27. Merie R, Browne L, Cardoso JS, Cardoso MJ, Chin $Y$, Clark C, et al. Proposal for a gold standard for cosmetic evaluation after breast conserving therapy: Results from the St George and Wollongong Breast Boost trial. J Med Imaging Radiat Oncol. 2017;61(6):819-25. 
28. Sacchini V, Luini A, Tana S, Lozza L, Galimberti $\mathrm{V}$, Merson $\mathrm{M}$, et al. Quantitative and qualitative cosmetic evaluation after conservative treatment for breast cancer. Eur J Cancer. 1991;27(11):1395400.

29. Yang J, Zhang R, Shen J, Hu Y, Lv Q. The ThreeDimensional Techniques in the Objective Measurement of Breast Aesthetics. Aesthetic Plast Surg. 2015;39(6):910-5.

30. Eder M, Waldenfels FV, Swobodnik A, Kloppel M, Pape AK, Schuster T, et al. Objective breast symmetry evaluation using 3-D surface imaging. Breast. 2012; 21(2):152-8.

31. Soror T, Kovacs G, Kovacs A, Seibold N, Melchert C, Baumann K, et al. New objective method in reporting the breast cosmesis after breastconservative treatment based on nonstandardized photographs: The Objective Breast Cosmesis Scale. Brachytherapy. 2016;15(5):631-6.

32. Pozzobon AV, Sabino Neto $M$, Veiga DF, Abla $L E$, Pereira JB, Biasi TL, et al. Magnetic resonance images and linear measurements in the surgical

Received in: 27/06/2020

Accepted for publication: 05/11/2020

Conflict of interest: no.

Funding source: none. treatment of breast asymmetry. Aesthetic Plast Surg. 2009;33(2):196-203.

33. Losken A, Fishman I, Denson DD, Moyer HR, Carlson GW. An objective evaluation of breast symmetry and shape differences using 3-dimensional images. Ann Plast Surg. 2005;55(6):571-5.

34. Catanuto $G$, Spano A, Pennati A, Riggio E, Farinella GM, Impoco G, et al. Experimental methodology for digital breast shape analysis and objective surgical outcome evaluation. J Plast Reconstr Aesthet Surg. 2008;61(3):314-8.

35. Cardoso MJ, Cardoso JS, Vrieling C, Macmillan D, Rainsbury D, Heil J, et al. Recommendations for the aesthetic evaluation of breast cancer conservative treatment. Breast Cancer Res Treat. 2012;135(3):629-37.

36. Cardoso MJ, Cardoso JS, Oliveira HP, Gouveia P. The breast cancer conservative treatment. Cosmetic results - BCCT.core - Software for objective assessment of aesthetic outcome in breast cancer conservative treatment: A narrative review. Comput Methods Programs Biomed. 2016;126:154-9.

\section{Mailing address:}

René Aloisio da Costa Vieira

E-mail: reneacv@terra.com.br

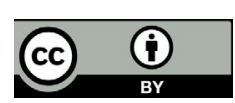

